\title{
Hubungan Anemia dengan Kejadian Bayi Berat Lahir Rendah pada Kehamilan Aterm di RSUD Achmad Darwis Suliki
}

\author{
Maryam Syifaurrahmah, Yusrawati, Zulkarnain Edward
}

\begin{abstract}
Abstrak
Anemia pada ibu hamil adalah kondisi ibu dengan kadar hemoglobin $(\mathrm{Hb})$ dalam darah $<11,0 \mathrm{~g} \%$. Masalah yang dihadapi oleh pemerintah Indonesia adalah tingginya prevalensi anemia pada ibu hamil yang merupakan masalah kesehatan utama yang berhubungan dengan kejadian bayi berat lahir rendah (BBLR). Bayi berat lahir rendah memiliki efek jangka pendek maupun panjang terhadap bayi tersebut dengan tingkat morbiditas dan mortalitas yang tinggi. Penelitian ini menggunakan desain retrospektif observasional dengan mengumpulkan data rekam medis ibu hamil aterm yang melahirkan di RSUD Achmad Darwis Suliki Kabupaten Lima Puluh Kota periode Januari - Desember 2013. Dari 73 sampel ibu hamil aterm anemia dan tidak anemia didapatkan nilai rerata berat bayi pada ibu hamil aterm anemia adalah 2722 gram dan rerata berat badan bayi pada ibu hamil aterm tanpa anemia adalah 2967 gram. Hasil analisis bivariat dengan uji Chi Square didapatkan nilai p:0,047 $(p<0,05)$ dengan rasio prevalensi sebesar 1,7. Disimpulkan bahwa terdapat hubungan bermakna antara anemia pada ibu hamil aterm dengan berat bayi lahir rendah di RSUD Suliki Kabupaten Lima Puluh Kota
\end{abstract}

Kata kunci: Anemia, hamil aterm, BBLR.

\begin{abstract}
Anaemia in pregnancy is a condition where hemoglobin concentration in blood $<11.0 \mathrm{gr} \%$. Indonesia government has an issue about the high prevalence of anaemia in pregnancy which is the main issue correlates to the low birth baby weight. Low birth baby weight has a short and long term effects with high risk of morbidity and mortality. This analytic research with observational retrospective design obtaining datas from medical records of aterm pregnant mother who gave a birth in RSUD Achmad Darwis Suliki Kabupaten Lima Puluh Kota in a period from January Desember 2013. From 73 samples of aterm pregnant mother who had anaemia and non anaemia, known mean of baby weight in normal aterm pregnant mothers who had anaemia is 2722 gram and mean of baby weight from aterm pregnant mothers without anaemia is 2967 gram. The result of bivariate analysis by Chi-Square test with $p$-value : $0.047(<0.05)$ and prevalence ratio is 1.7 . It can concluded that there is a significant correlation between anaemia in aterm pregnancy and low birth baby weight in RSUD Achmad Darwis Suliki Kabupaten Lima Puluh Kota.
\end{abstract}

Keyword: Anaemia, Aterm Pregnancy, Low Birth Baby Weight

Affiliasi penulis : Fakultas Kedokteran Universitas andalas

Korespondensi : Maryam Syifaurrahmah,

email:maryamsyifa@gmail.com. Telp: 085763100272

\section{Pendahuluan}

Anemia pada kehamilan adalah salah satu masalah yang umum terjadi di negara-negara berkembang'. Menurut World Health Organization (WHO), anemia pada ibu hamil adalah kondisi ibu dengan kadar hemoglobin $(\mathrm{Hb})$ dalam darah $<11,0 \mathrm{~g} \%$ atau keadaan jumlah eritrosit lebih rendah dari normal sebagai akibat kekurangan satu atau lebih zat pembentukan darah, salah satunya zat besi². Masalah yang dihadapi oleh pemerintah Indonesia adalah tingginya prevalensi anemia ibu hamil dan sebagian besar penyebabnya adalah kekurangan zat besi yang diperlukan untuk pembentukan hemoglobin sehingga yang ditimbulkannya disebut anemia defisiensi besi ${ }^{3}$. 
Anemia dalam kehamilan merupakan masalah kesehatan utama yang berhubungan dengan kejadian BBLR ${ }^{1}$. World Health Organization (WHO) menyatakan bahwa dua pertiga dari ibu hamil di Indonesia menderita anemia. Berdasarkan jumlah tersebut sekitar 20\% nya berakhir pada kejadian BBLR. Persentase dari masing-masing faktor risiko untuk kejadian BBLR diantaranya anemia dalam kehamilan $(67 \%)$, primipara $(31.96 \%)$, dan tidak mengikuti ante natal care $(29.80 \%)^{4}$.

Anemia merupakan kasus yang dapat dicegah dengan mudah namun kejadiannya banyak. Berbagai kebijakan yang telah dicanangkan tidak dapat mengurangi angka kejadian anemia dalam kehamilan secara signifikan ${ }^{5}$. Sebagian besar ibu hamil tidak mengetahui mengenai BBLR sebagai akibat dari anemia yang dideritanya saat hamil. Padahal BBLR merupakan salah satu penyebab terbesar morbiditas dan mortalitas dalam lima tahun terakhir. Selain itu, tenaga kesehatan juga tidak menekankan tentang BBLR pada saat ante natal care ${ }^{6}$.

anemia defisiensi zat besi merupakan salah satu masalah dengan frekuensi yang cukup tinggi yaitu dan makin meningkat seiring dengan pertambahan usia kehamilan. Proporsi kejadian berat bayi lahir rendah lebih besar pada ibu hamil yang menderita anemia. Perbedaan berat lahir bayi tidak signifikan kecuali pada ibu hamil trimester ketiga dan aterm ${ }^{7}$. Wanita hamil cenderung terkena anemia pada trimester ketiga dan menjelang aterm karena pada masa ini janin menimbun cadangan zat besi untuk dirinya sendiri sebagai persediaan bulan pertama sesudah lahir ${ }^{8}$

Prevalensi anemia pada kehamilan di negara berkembang sebesar 36\% dari perkiraan populasi sebesar 3800 juta orang. Berdasarkan laporan Survei Kesehatan Rumah Tangga (SKRT) tahun 2004, angka kejadian anemia pada kehamilan di Indonesia berjumlah sekitar $40.10 \%{ }^{3}$. Prevalensi bayi berat lahir rendah (BBLR) di Indonesia tahun 2009 sebesar 25\%. Hasil penelitian riset kesehatan dasar (Riskesdas) tahun 2007 menunjukkan angka kejadian bayi berat lahir rendah (BBLR) di Indonesia sebesar $11.50 \%$ dari lima juta bayi lahir setiap tahunnya sedangkan di Sumatera Barat kejadian bayi berat lahir rendah (BBLR) sebanyak 1.61\%. Data Dinas Kesehatan
Kabupaten Lima Puluh Kota menunjukkan bahwa dalam tiga tahun terakhir ini terjadi peningkatan kejadian anemia ibu hamil dan BBLR, yakni pada tahun 2011 terdapat kasus anemia 1142 dari 5961 kelahiran dan 160 BBLR; pada tahun 2012 terdapat 1705 kasus dari 6066 kelahiran dan 191 BBLR; dan pada hingga september 2013 terjadi 201 kasus BBLR disertai 1614 kasus anemia dari 4693 kelahiran.

Bayi Berat Lahir Rendah (BBLR) dapat mengakibatkan terjadinya insiden sepsis umbilikalis, gangguan pada mata (ophtalmology), gangguan pendengaran $^{9}$, diare, ikterus neonatorum, infeksi traktus respiratorius, dan yang paling sering ditemukan berupa asfiksia neonatorum ${ }^{10}$. Akibat jangka panjang bayi berat lahir rendah (BBLR) antara lain terhadap tumbuh kembang anak, risiko penyakit jantung di masa yang akan datang dan penurunan kecerdasan ${ }^{11}$. Bayi berat lahir rendah (BBLR) merupakan faktor penting dalam morbiditas dan mortalitas perinatal di negara berkembang ${ }^{12}$. Bayi berat lahir rendah (BBLR) berisiko kematian 35 kali lebih tinggi dibandingkan dengan bayi dengan berat lahir normal ${ }^{13}$. Di negara berkembang diperkirakan setiap 10 detik terjadi satu kematian bayi akibat penyakit atau infeksi yang berhubungan dengan bayi berat lahir rendah (BBLR) ${ }^{14}$.

Anemia pada kehamilan dapat meningkatkan insiden BBLR terkait dengan gangguan transfer hemoglobin ke janin melalui plasenta ${ }^{15}$. Sejalan dengan penelitian menunjukkan bahwa anemia pada trimester ketiga memiliki hubungan yang positif dengan berat badan lahir bayi. Ibu hamil dengan anemia melahirkan bayi dengan berat badan yang lebih rendah daripada ibu hamil normal ${ }^{16}$.

\section{Metode}

Penelitian ini merupakan penelitian crosssectional dengan mengambil data dari status rekam medis ibu hamil aterm dengan anemia dan tanpa anemia yang melahirkan di RSUD Achmad Darwis Suliki periode 1 Januari 2013 - 31 Desember 2013. Subyek penelitian ini adalah 73 ibu hamil anemia dan tanpa anemia dengan data rekam medis lengkap, terdapat data $\mathrm{Hb}$, dan berat bayi lahir. Data yang didapatkan diolah dengan SPSS untuk mengetahui hubungan anemia dengan kejadian bayi berat lahir rendah pada kehamilan aterm. Hasil analisis statistik 
yang diperoleh akan disajikan dalam bentuk gambar dan tabel.

\section{Hasil}

Penelitian ini mendapatkan ibu hamil dengan anemia yang tercatat di RSUD Suliki pada tahun 2013 adalah sebanyak 261 orang dari 472 persalinan.

\section{Analisis Univariat}

Berdasarkan analisis univariat terhadap distribusi berat lahir bayi diperoleh nilai rata-rata adalah 2967 gram pada ibu hamil tanpa anemia dan 2722 gram pada ibu hamil dengan anemia. Dari 73 ibu hamil anemia yang diambil sebagai sampel, berikut tabel yang menunjukkan distribusi frekuensi ibu hamil anemia berdasarkan klasifikasi anemia.

Tabel 1. Distribusi Frekuensi lbu hamil dengan anemia berdasarkan Klasifikasi Hb Sahli

\begin{tabular}{ccc}
\hline Klasifikasi & \multicolumn{2}{c}{ Frekuensi } \\
\cline { 2 - 3 } Anemia & $\mathbf{n}$ & $\%$ \\
\hline Anemia ringan & 54 & 73.9 \\
Anemia sedang & 18 & 24.6 \\
Anemia berat & 1 & 1.3 \\
\hline Total & 73 & 100 \\
\hline
\end{tabular}

Dari tabel 1 dapat dilihat bahwa ibu hamil anemia terdiri dari anemia ringan 54 orang (73,9\%), anemia sedang 18 orang (24,6\%), dan anemia berat sebanyak 1 orang $(1,3 \%)$.

Tabel 2.Distribusi Frekuensi lbu Hamil berdasarkan berat bayi lahir

Dari tabel 2 dapat dilihat bahwa ibu hamil dengan anemia ringan yang melahirkan bayi berat lahir rendah (BBLR) adalah sebanyak 17 orang (31.5\%) dan melahirkan bayi non BBLR sebanyak 37 orang (68.5\%). Anemia sedang melahirkan 6 BBLR (33.3\%) dan 12 bayi non BBLR (66.7\%). Sedangkan satu ibu hamil dengan anemia berat melahirkan bayi berat lahir rendah (BBLR).

\section{Analisis Bivariat}

Berikut adalah tabel analisis bivariat yang menunjukkan perbedaan berat bayi lahir pada ibu hamil dengan anemia dan tanpa anemia.

Tabel 3. Perbedaan berat lahir bayi pada ibu hamil anemia dan tanpa anemia

\section{Berat Lahir Bayi

non Total

\section{BBLR BBLR}

\begin{tabular}{lccccccc} 
& $\mathbf{n}$ & $\boldsymbol{\%}$ & $\mathbf{N}$ & $\boldsymbol{\%}$ & $\mathbf{n}$ & $\boldsymbol{\%}$ & \\
\hline Anemia & 24 & 32.9 & 49 & 67.1 & 73 & 100 & \\
non - & & & & & & & 0.047
\end{tabular}

$\begin{array}{lllllll}\text { Anemia } & 14 & 19.2 & 59 & 80.8 & 73 & 100\end{array}$

Dari tabel diatas dapat dilihat bahwa proporsi bayi dengan berat lahir rendah lebih banyak terjadi pada ibu hamil dengan anemia dibandingkan dengan ibu hamil tanpa anemia. Pada hasil pengolahan data menggunakan chi-square didapatkan nilai $p=0.047$ (dimana nilai $p$ dianggap bermakna bila $p<0.05$ ) yang berarti bahwa terdapat hubungan bermakna antara anemia pada ibu hamil dengan berat bayi lahir rendah.

\section{Pembahasan}

\section{Analisis Univariat}

\begin{tabular}{|c|c|c|c|c|c|c|c|}
\hline & & \multicolumn{6}{|c|}{ Anemia Ibu Hamil } \\
\hline & & \multicolumn{2}{|c|}{ Ringan } & \multicolumn{2}{|c|}{ Sedang } & \multicolumn{2}{|c|}{ Berat } \\
\hline & & $\mathbf{n}$ & $\%$ & $\mathbf{n}$ & $\%$ & $\mathbf{n}$ & $\%$ \\
\hline $\begin{array}{l}\text { Berat } \\
\text { Lahir }\end{array}$ & BBLR & 17 & 31.5 & 6 & 33,3 & 1 & 100 \\
\hline \multirow[t]{3}{*}{ Bayi } & Non- & & & & & & \\
\hline & BBLR & 37 & 68.5 & 12 & 66,7 & 0 & 0 \\
\hline & Total & 54 & 100 & 18 & 100 & 1 & 100 \\
\hline
\end{tabular}

bahwa anemia ringan sebagai jenis anemia terbanyak yang diderita oleh 73 ibu hamil dengan anemia. Data penelitian ini juga menunjukkan bahwa anemia ringan, sedang, dan berat tidak berpengaruh terhadap prevalensi kejadian BBLR dan non BBLR yang terjadi. 
Penelitian ini juga menyebutkan bahwa ratarata berat badan bayi pada ibu hamil anemia dan tanpa anemia adalah 2722 gram dan 2967 gram. Berat badan ini tergolong kategori normal (>2500gram). Hal ini dapat dijelaskan karena jenis hemoglobin di intra uterin yang berbeda dengan hemoglobin maternal. Janin memiliki $\mathrm{HbF}$ yang memiliki afinitas tinggi terhadap oksigen karena lemahnya ikatan dengan 2,3 BPG (BiphosphoGliseric Acid). HbF menyebabkan janin tetap mendapatkan pasokan oksigen yang mencukupi walaupun pada keadaan $\mathrm{HbA}$ pada maternal hanya mengikat sedikit oksigen ${ }^{17}$.

\section{Analisis Bivariat}

Berdasarkan penelitian yang dilakukan secara retrospektif observasional di RSUD Achmad Darwis Suliki terhadap ibu hamil aterm anemia dan tanpa anemia, terdapat masing-masing 73 kasus ibu hamil aterm anemia dan tanpa anemia yang memenuhi kriteria untuk dijadikan sampel pada penelitian ini. Secara statistik berdasarkan uji chi square terdapat perbedaan yang bermakna antara berat bayi lahir rendah pada ibu hamil aterm anemia dan tanpa anemia, didapatkan nilai $p=0.047(p<0,05)$ dengan rasio prevalensi 1.7. Maknanya, terdapat hubungan bermakna antara anemia pada ibu hamil dengan kejadian bayi berat lahir rendah. Ibu hamil dengan anemia 1.7 kali lebih berisiko melahirkan BBLR dibandingkan ibu hamil tanpa anemia.

Hasil ini sesuai dengan teori bahwa anemia dalam kehamilan merupakan salah satu faktor risiko bayi berat lahir rendah4 ${ }^{4}$. Anemia yang terjadi selama kehamilan dikarenakan terjadinya peningkatan kebutuhan zat besi hampir tiga kali lipat untuk pertumbuhan janin dan keperluan ibu hamil3. Kenaikan volume darah selama kehamilan akan meningkatkan kebutuhan zat besi. Selama kehamilan, seorang ibu hamil menyimpan zat besi sebesar 1.000 mg yang berfungsi untuk keperluan janin, plasenta dan hemoglobin ibu sendiri. Jumlah zat besi pada bayi baru lahir kira-kira sebesar 300 mg sedangkan jumlah zat besi yang diperlukan ibu untuk mencegah anemia akibat meningkatnya volume darah adalah sekitar 500 mg. Apabila jumlah tersebut tidak dapat terpenuhi maka akan terjadi anemia defisiensi besi dalam kehamilan².

\section{Kesimpulan}

1. Frekuensi bayi berat lahir rendah (BBLR) pada ibu hamil anemia adalah 24 orang (32.9\%)

2. Frekuensi bayi berat lahir rendah (BBLR) pada ibu hamil tanpa anemia adalah 14 orang (19.2\%)

3. Frekuensi bayi berat lahir normal pada ibu hamil anemia adalah 49 orang (67.1\%).

4. Frekuensi bayi berat lahir normal pada ibu hamil tanpa anemia adalah 59 orang (80.8\%).

5. Berdasarkan analisis statistik terdapat hubungan yang bermakna antara anemia pada ibu hamil aterm dengan kejadian bayi berat lahir rendah di RSUD Achmad Darwis Suliki Kabupaten Lima Puluh Kota.

\section{Daftar Pustaka}

1. Owais A, Umay K, Kalsoom U. Effect of maternal anaemia on birth weight. Ayub Medical College. 2011; 1:23.

2. Cunningham FG, Gant NF.Obstetri Williams 21st edition. Jakarta: EGC. 2010.

3. Departemen Kesehatan RI. Program Penanggulangan Anemia Gizi pada Wanita Usia Subur. Jakarta: Direktorat Gizi Masyarakat dan Binkesmas. 2003.

4. Elhassan, Amer O, Haggaz AD, Adam I, et al. Anaemia and Low Birth Baby Weight in Medani, Sudan. BioMed Central Research. 2010; 3:81.

5. Bhalerao A, Khawthalkar A, Ghike S, Joshi S. Anemia during pregnancy: Most preventable yet Most Prevalent. Contemporarry Original Study Journal. 2011; 2: 75-77.

6. Gundani HV, Mutowo J. Low Birth Weight Knowledge among Postnatal Mothers in a Resource Restricted Urban Setting in Zimbabwe. International journal of Nursing and Midwifery. 2012; 4:40-44

7. Kumar KJ, Asha N, Murthy DS, Sujatha MS, et al. The Micronutrient Level in the third trimester of Pregnancy and the Assesment of Neonatal 
Outcomes. International Journal of Preventive Medicine. 2013; 4:2.

8. Theressa O, Scholl, Reilly T. Anaemia, Iron, and Pregnancy Outcomes. The American Journal Society for Natural Sciences. 2000.

9. Goldenberg RL, Culhane JF. Low Birth Weight in United States. The American Journal of Clinical Nutrition. 2007; 85: 5845-5905.

10. Bari MI, Ulah MA, Khatun M. Morbidity and Mortality of Low Birth Weight Baby. The Journal of Teachers Association. 2008; 21.

11. Setyawati T. Faktor-faktor yang mempengaruhi Bayi Berat Lahir Rendah. 2001.

12. Singsh SD, Shresta S, Maharata SB. Incidence and Risk Factor of Low Birth Weight Babies Born in Dulikhel Hospital. Journal of Institue of Medicine. 2010; 32: 39-42.

13. Pantiawati. Bayi dengan BBLR. Jogjakarta: Nuha Medika. 2010.

14. Siza JE. Risk Factor Associated with Low Birth Weight of Neonates among Pregnant Women attending a Referral Hospital in Northern Tanzania. Tanzania Journal of Health Research. 2008;10.

15. Nurhayati. Faktor Resiko lbu Hamil terhadap Kejadian Bayi Berat Lahir Rendah di Puskesmas Singkawang Pontianak. Poltekes Pontianak.2009.

16. Sahu KK, Idriz MZ, Agaswal M, et al. Effect of Anaemia during Pregnancy on Gestation Size and Birth Weight of Babies in Rural Luck Now. World Journal of Pharmacy and Pharmakeutical Sciences. 2013; 2:6.

17. Hoffman R, Edward J, Benz Jr, et al. Hematology Basic Priciples and Practice 6th edition. USA: Elsevier Saunders. 2013 